\title{
Comprehensive Clinical Study of Postmenopausal Bleeding Excluding Carcinoma Cervix.
}

\author{
Dr.Kavitha. ${ }^{1}$, Dr.G.C.Prabhakar ${ }^{2}$, Dr. Shaivalini.k ${ }^{3^{*}}$, Dr.Suprada.k ${ }^{4}$ \\ ${ }^{1}$ Professor in Gynecology and Obstetrics, Mamata Medical College \& General Hospital, Khammam, \\ ${ }^{2}$ Head of Department in Gynecology and Obstetrics, Mamata Medical College \& General Hospital, Khammam, \\ ${ }^{3}$ Post graduate in gynecology and obstetrics, Mamata Medical College \& General Hospital, Khammam, \\ ${ }^{4}$ Post graduate in gynecology and obstetrics, Mamata Medical College \& General Hospital, Khammam,
}

\begin{abstract}
Introduction: Menopause:-Defined as the permanent cessation of menstruation resulting from loss of ovarian activity. Menopause normally occurs between the age of 45 to 50 yrs. The age of menopause varies with geographical, racial,nutritional factors. Objectives: To evaluate and to know the incidence of various causes of Post menopausal bleeding excluding carcinoma cervix. Methods: The Study was conducted on all post menopausal women registered to gynecology out Patient department of Mamata General Hospital who fulfilled the inclusion criteria with history and clinical examination. With informed consent from the patient, data analysis will be done by appropriate statistical methods. Design \&Duration: This was a Prospective Study of 50 cases were taken in a duration from the Period of 2011-July to 2013-August. RESULTS: Maximum number of patients attained menopause between the age group of 50-54 years. Mean age at menopause was 52.5 years. Most of the women had postmenopausal bleeding within three years of attaining menopause. Out of 50 patients 7 were diagnosed to have, malignancy and remaining were due to benign causes. CONCLUSION : In this present study the incidence of malignancy causing postmenopausal bleeding was $14 \%$ and benign causes was $86 \%$. Universal screening of all post menopausal women with bleeding for genital tract malignancy is mandatory. Screening should be started effectively from reproductive age group.
\end{abstract}

Key words: menopause, post menopausal bleeding , universal screening

\section{Introduction}

Menopause : Defined as the permanent cessation of menstruation resulting from loss of ovarian activity (WHO, 1981). Menopause Derived from Greek men `month` and `pauso `to stop and means cessation of menstruation. Menopause normally occurs between the ages of 45 to 50 years, the average age being 47 years. Sometimes a woman can have menstruation well beyond the age of 50 years.

Pre, Peri And Post Menopause:- Applied respectively to the periods immediately before, around and after cessation of menstruation. Clinical impression has suggested that mothers and daughters tend to experience menopause at same age. Post menopausal bleeding is not normal, so any episode of bleeding should be brought to the attention of gynecologist. Women on estrogen replacement therapy are more likely to experience post menopause bleeding.

Early menopause: This was the period within 2 years after menopause. Senescence: After the age of 60 years. Some use 65 years as the cutoff age. Another menopause staging was first published by Dr. Behram Anklesaria in 1997 .STAGE I : Earliest perimenopausal symptom (usually vasomotor instability or menstrual irregularity ) to menstrual cessation (menopause) lasts from 3 to 5 years. STAGE II : " Five years after menopause". This stage was further sub -divided into stage -II A and stage II B .STAGE II A : "From the cessation of menstruation upto one year"with vasomotor instability and urethral syndrome. STAGE II B: From end of stage II A upto four years with atrophic symptoms, vaginitis, dyspareunia, Urinary symptoms, Weight gain, Skin and hair changes STAGE III : "From 5 years after menopause upto an indefinite period; probably life time " with atrophic symptoms, ischemic heart disease and early osteoporosis , cerebrovascular changes and Alzheimer's disease. Benign conditions are most frequent causes of Postmenopausal bleeding but endometrial cancer is the most serious potential underlying cause.

Risk factors of postmenopausal bleeding are conditions typically associated with chronic elevations of endogenous estrogen levels or increased estrogen action at the level of the endometrium or exogenous estrogen therapy . These include obesity, history of chronic anovulation.,diabetes mellitus, estrogen-secreting tumors, exogenous estrogen unopposed by progesterone,Tamoxifen use,a family history of Lynch type II syndrome (hereditary nonpolyposis colorectal, ovarian, or endometrial cancer)

\section{Etiology Of Post Menopausal Bleeding}

Genital Tract Causes : VULVA:- Vulvitis,Trauma ,Benign and Malignant lesions .VAGINA:-Foreign body such as ring Pessary for Prolapse, senile Vaginits, Vaginal cancer and post radiation vaginitis. CERVIX :- 
Benign cervical erosion,Polyp,Cervicitis,Decubitus ulcer in case of Prolapse and cervical malignancy. UTERUS:- Senile Endometritis Tubercular endometritis, endometrial polyp, endometrial hyperplasia and endometrial carcinoma. DUB: - Mostly Metropathia Haemorrhagica FALLOPIAN TUBE:- Malignancy. OVARY: - Benign ovarian tumors such as Brenner tumor, hormone secreting granulosa tumors and theca cell tumors, malignant tumors.OTHER CAUSES :Hypertension,Blood Dyscrasia. URINARY TRACT CAUSES : Urethral Caruncle, Papilloma and Carcinoma of Bladder.GASTROINSTESTINAL CAUSES: Bowel :Bleeding from hemorrhoids and fissures. Rectal cancer may be misinterpreted by the patient as vaginal bleeding. HORMONAL: Indiscriminate or prolonged use of estrogen.

\section{Materials And Methods}

The study was conducted on all postmenopausal women registered to gynecology out- patient department with abnormal uterine bleeding who attained menopause naturally, history and clinical examination were included. Women who were diagnosed carcinoma cervix were excluded.

\section{Results}

This study included 50 cases of post menopausal women with bleeding per vaginum and thorough evaluation was done to know the incidence of various causes for post menopausal bleeding. In present study the duration of occurance of bleeding from menopause varies from less than one year to more than five years. The maximum number of women had post menopausal bleeding in between 1- 3 years. Most of them reported with the complaints of bleeding per vaginum. The cause of postmenopausal bleeding were commonly benign causes mostly local causes such as cervical\& vaginal changes due to menopause, and secondly the malignant causes .In the malignant causes the most common malignancy documented in my study was ovarian malignancy. In present study the cause due to malignancy were seven. Out of seven malignant causes, four were ovarian malignancies out of which were 1) classical clear cell granulosa tumor, 2) left serous cystadenocarcioma,3)right ovarian adenocarcinoma ovary, 4) ovarian carcinoma,two were endometrial carcinomas and one was vaginal carcinoma. In women with postmenopausal bleeding, percentage of malignancy was $14 \%$. This shows an indication to screen all Indian postmenopausal women for malignancy of genital tract.

TABLE-1 BASED ON THE ONSET OF SYMPTOMS FROM THE AGE OF MENOPAUSE

\begin{tabular}{|l|l|l|l|}
\hline S.NO & $\begin{array}{l}\text { DURATION OF } \\
\text { MENOPAUSE }\end{array}$ & \multicolumn{1}{|c|}{$\begin{array}{l}\text { NO.OF } \\
\text { PATIENTS }\end{array}$} & PERCENTAGE \\
\hline 1 & Less than one year & 5 & $10 \%$ \\
\hline 2 & 1 -3 YRS & 28 & $56 \%$ \\
\hline 3 & 3 -5 YRS & 10 & $20 \%$ \\
\hline 4 & More than 5yrs & 7 & $14 \%$ \\
\hline \multicolumn{2}{|l|}{ TOTAL NO. } & 50 & $100 \%$ \\
\hline
\end{tabular}

TABLE-2 BASED ON THE CAUSE OF BLEEDING

\begin{tabular}{|l|l|l|l|}
\hline S.NO & CAUSES & NO.OF PATIENTS & PERCENTAGE \\
\hline 1 & Malignant & 7 & $14 \%$ \\
\hline 2 & Benign & 43 & $86 \%$ \\
\hline \multicolumn{2}{|l|}{ TOTAL NO. } & 50 & $100 \%$ \\
\hline
\end{tabular}

TABLE-3 MALIGNANT CAUSES OF POST -MENOPAUSAL BLEEDING

\begin{tabular}{|l|l|l|l|}
\hline S.N.O & CAUSES & NO.OF PATIENTS & PERCENTAGE \\
\hline 1 & Vaginal carcinoma & 1 & $14.4 \%$ \\
\hline 2 & Ovarian carcinoma & 4 & $57.1 \%$ \\
\hline 3 & Endometrial carcinoma & 2 & $28.5 \%$ \\
\hline TOTAL N.O & & 7 & $100 \%$ \\
\hline
\end{tabular}

TABLE-4 INCIDENCE OF ETIOLOGY OF THE POSTMENOPAUSAL BLEEDING

\begin{tabular}{|l|l|l|l|}
\hline S.NO & CAUSE & NO.OF PATIENTS & PERCENTAGE \\
\hline 1 & Endometrial polyps & 4 & 8 \\
\hline 2 & Adenomyosis & 2 & 4 \\
\hline 3 & Endometrial hyperplasia & 5 & 10 \\
\hline 4 & Senile endometritis & 2 & 4 \\
\hline 5 & Degenerative broad ligament & 1 & 2 \\
\hline
\end{tabular}




\begin{tabular}{|l|l|l|l|}
\hline & fibroid & & \\
\hline 6 & Cervical polyps & 11 & 22 \\
\hline 7 & Cervical fibroid & 1 & 2 \\
\hline 8 & Chronic cervicitis & 5 & 10 \\
\hline 9 & Cervical erosion & 4 & 8 \\
\hline 10 & Pyometra & 3 & 6 \\
\hline 11 & Atrophic cervicitis & 2 & 4 \\
\hline 12 & Senile vaginitis & 2 & 4 \\
\hline 13 & Atrophic vaginitis & 1 & 2 \\
\hline 14 & Vaginal carcinoma & 1 & 2 \\
\hline 15 & Endometrial carcinoma & 2 & 4 \\
\hline 16 & Ovarian carcinoma & 4 & 8 \\
\hline Total & & 50 & \\
\hline
\end{tabular}

\begin{tabular}{|l|l|l|l|}
\multicolumn{5}{c}{ TABLE-5 INCIDENCE OF MALIGNANCY } \\
\hline S.NO & AUTHOR & YEAR OF STUDY & \% OF MALIGNANCY \\
\hline 1 & $\begin{array}{l}\text { KANTOR } \\
\text { KLAWANS }\end{array}$ & 1932 & $68.4 \%$ \\
\hline 2 & TYLOR \& MILLER & 1938 & 63 \\
\hline 3 & ISREAL\& WEBER & 1956 & 33.5 \\
\hline 4. & PAYNE \& WRIGHT & 1959 & 30 \\
\hline 5 & KINTIS & 1982 & 14.5 \\
\hline 6 & SENGUPTA & 1989 & 42 \\
\hline 7 & $\begin{array}{l}\text { BURTHANKUR \& } \\
\text { GOGOIL }\end{array}$ & 1983 & 14.25 \\
\hline 8 & PRESENTSTUDY & 2013 & 14 \\
\hline
\end{tabular}

TABLE-6 BASED ON METHOD OF THE MANAGEMENT

\begin{tabular}{|l|l|l|l|}
\hline S.NO & $\begin{array}{l}\text { MODE OF } \\
\text { MANAGEMENT }\end{array}$ & NO. OF PATIENTS & PERCENTAGE \\
\hline 1 & Medical management & 10 & $20 \%$ \\
\hline 2 & Surgical dilatation \& & 35 & $70 \%$ \\
\hline 3 & $\begin{array}{l}\text { Cervical } \\
\text { drainage of pus }\end{array}$ & 2 & $4 \%$ \\
\hline 4 & Radiotherapy & 3 & $6 \%$ \\
\hline TOTAL NO. & 50 & $100 \%$ \\
\hline
\end{tabular}

TABLE-7 METHOD OF MANAGEMENT FOR MALIGNANCY

\begin{tabular}{|l|l|l|}
\hline S.NO & $\begin{array}{l}\text { MODE OF } \\
\text { MANAGEMENT }\end{array}$ & NO.OF PATIENTS \\
\hline 1 & Medical & 0 \\
\hline 2 & Surgery & 4 \\
\hline 3 & Surgery+Radiotherapy & 3 \\
\hline Total & & 7 \\
\hline
\end{tabular}

TABLE-8 METHODS OF MANAGEMENT FOR BENIGN CAUSES

\begin{tabular}{|l|l|l|}
\hline S.NO & MANAGEMENT & NO.OF PATIENTS \\
\hline 1 & Medical & 10 \\
\hline 2 & Surgical & 31 \\
\hline 3 & Cervical dilatation\& drainage & 2 \\
\hline
\end{tabular}

\section{Discussion}

Maximum number of patients(27) attained menopause in between the age group of 50 -54. Most of the women had postmenopausal bleeding within 3 yrs of attaining menopause. Out of 50 women most of them were multiparous 36.Maximum number of patients had sudden cessation of menstruation.The mean age at menopause was 52.5 years. The earliest age at menopause was 45 years and delayed age at menopause was 66years.The duration of menopause varied from 7 months to 12 years.In majority of cases bleeding 
occurred within 1- 3 years of menopause.All malignant cases of postmenopausal bleeding had their bleeding episodes greaterthan 5 years after attainment of menopause.Most of them had uneventful menopause, very few of them had perimenopausal menstrual irregularity.Out of 50 cases it was found that 2 cases had uterus enlargement.

Malignancy was found in $14 \%$ of cases of post menopausal bleeding.Out of them vaginal carcinoma was 1, endometrial carcinoma 2 and 4 ovarian carcinoma.The endometrial pathology \& uterine in post menopausal bleeding was as follows Endometrial polyp - 5,Adenomyosis - 2,Endometrial hyperplasia 5 ,Senile endometritis - 2,Degenerative broad ligament fibroid -1, The local cervical and vaginal causes of post menopausal bleeding in present study, Cervical polyps - 11, Cervical fibroid - 1, Chronic cervicitis - 5, Cervical erosion - 3,Atrophic cervicitis - 2,Pyometra - 3,Senile vaginitis - 2,Atrophic vaginitis - 1 .

In present study the majority of mode of management of postmenopausal bleeding was surgical due to various factors \& medical management was opted by only 10 women. Radiotherapy was adviced to 3 patients due to advanced stage of malignancy. Out of seven patients seven underwent surgical management . only three of them had radiotherapy along with surgical management. For radiotherapy we referred to oncology institute. Out of 50 patients 43 had postmenopausal bleeding due to benign cause of them 10 were managed medically \& remaining were managed surgically

\section{Conclusion}

In this present study majority of the patients reached menopause before 54 years of age, ( mean age 52.5 years ). Papsmear and visual inspection was done for all patients.Benign lesions presented in combination with each other. In this present study the incidence of malignancy causing postmenopausal bleeding was $14 \%$ and the incidence with benign causes was $86 \%$.Due to social taboos and illiteracy most of the women will not seek the medical assistance early, hence cancers have been reported at an advanced stage where survival chances are far less.

In India universal screening of all postmenopausal women with bleeding for genital tract malignancy is mandatory. The screening should be started effectively from reproductive age group.Health education , early detection of cancers and early intervention can reduce the deaths due to malignancy. The studies on geriatric oncology have to be intensified. This study shows necessity to expand the presently available cancer control programmes applying the modern technology to under privileged rural women

\section{Bibliography}

[1] Jeffcoate`s principles of gynaecology "menopause" chapter 53 seventh edition 2008 :863 -864.p.p

[2] Kinti`s . G.A and Calvert. W. 1982 : "post menopausal bleeding -one hospital - one year ". J. obstetrics gynaecology INDIA , 32 : 676 .P.P

[3] D.C .Dutta text book of gynaecology “postmenopausal bleeding "chapter 33 fifth edition; 532 -533 p.p.

[4] HAINES \& TALYER Obsterical \& gynaecological pathology $5^{\text {th }}$ edition.

[5] Edward : Novak`s Gynaec obs. Pathology textbook gynaecological practice.

[6] Gynaecol. Oncol.2004 Dec; 95(3) : 456-62.

[7] Cohen c.j, histological screening for endometrial cancer, gynaec.2: 279, 1974

[8] Novak's gynaecology $13^{\text {th }}$ edition.

[9] American journal obstetrics \& gynaecology : back reviews.

[10] Clinical and gynaecologic endocrinology \& Infertility leon speroff fourth edition.

[11] Bergman , A , and Brenner ,P.F. "LACERATIONS IN THE UROGENITAL SYSTEM" chapter -5 in menopause - physiology and pharmacology, Daniel. R. Mischell. Jr (Ed) Chicago : year book medical publishers, 1987: 67 -76 